\title{
MOBILE LEARNING AND THE FORMATION OF DIGITAL LITERACY IN A KNOWLEDGE SOCIETY
}

\author{
Valentina Milenkova and Boris Manov \\ South-West University, 66 Iv.Mihailov str., Blagoevgrad, Bulgaria
}

\begin{abstract}
The present article aims to show the emergence of digital technologies in university education as a way for the formation of digital literacy in the contemporary knowledge society. The article analyzes the changes, which occur in university education creating prerequisites for mobile learning. Special attention paid to distance learning, where teachers and learners use digital communication technologies and interactive learning tools.

Methodology is based on qualitative methods, under the national project "Digital Media Literacy in the context of "Knowledge Society": state and challenges", № КП-06-H25/4, 2018, funded by National Science Fund - Bulgaria. The respondents - lecturers and students assessed digital skills and environment in university education.

The main conclusions are that more efforts needed to improve the approaches to mobile learning, to create Internet security and to take into account the interests of learners.
\end{abstract}

\section{KEYWORDS}

Digitization, Mobile Learning, Digital literacy, Digital Competencies, Distance Education

\section{INTRODUCTION}

Public processes are characterized by an ongoing "digitization". This concept analyzes the interrelation between development of information technologies and communication, on the one hand, and transformations in culture and society on the other. The change in media consists of convergence between mobile communication technologies and the internet, which establish new communication networks and routines and become an integral part of life. The new environment requires the development of digital skills that enable effective use of ICT and information (Peicheva, Milenkova, 2017; Cartelli, 2013). Digitization, interactivity and virtuality are constantly opening up new possibilities and extending the boundaries of learning (Henriksen, 2011). Digital skills should be seen as directly related to the strengthening of information and communication technologies (ICT), which are a factor in access to wider and up-to-date knowledge, more effective and creative thinking, informed decision making in different problem situations. The integration of information and communication technologies into university teaching at all levels and in all areas of training requires the development of skills and competencies related to the knowledge and use of digital media. Very often mainly Internet is the basic source of information for preparing the classes and for the carrying out research tasks that are undertaken during different subjects at university; so the study processes, which take place in the institutions of both formal and non-formal education are closely linked with the digitization. The process itself of cooperation between media and education and the strengthening role of digital literacy as complementary educational processes is a subject of daily and systematic implementation and development in any particular educational situation.

Objectives of the present paper are: 1) To reveal mobile learning as an approach and real learning technology in modern education in the knowledge society. 2) To show the dimensions of the digitization in university learning. 3) To analyze the assessments and opinions of actors directly involved in educational processes. 


\section{BASIC CONSIDERATIONS}

Digital technologies reflect the level of development of the material environment and conditions and stimulate their improvement and modernization. History of technology shows a striving for rapid and comprehensive access to knowledge stored on different media.

The creation of the Internet has expanded the boundaries of digitization, and the combination of the Internet with individual conditions for access to information after the invention of personal computers and electronic personal devices has given unlimited access to all kinds and volumes of information. This resulted in the formation of a computer-based communication area. In terms of online communication is established the possibility of feedback in all forms of communication - text, audio-visual, multimedia.

Digital technology has changed the relatively static, dominant linear pattern of communication into a dynamic, multilevel, demanding and content-making model. (Livingstone, 2004).

The Knowledge Society is based on digitization and represents the interrelation between individuals and the pervasive and all-round application of computer technologies.

Knowledge society means that every area of public life and personal development is based on the targeted application of knowledge. Furthermore, it suggests sustainability of individual and social space and time, which builds dynamic balance between people, their artificial creations and nature.

The concept of "knowledge society" gains popularity as part of the political discourse presented by the institutions of the European Union (EU) and influential international institutions such as the Organization for Economic Cooperation and Development (OECD) and the World Bank (WB). Knowledge is at the center of economic development policies and social growth. In this sense - investing in human capital through education and training, as well as investment in research and development began to be seen as a central factor for economic growth. This necessitates the need for the creation of policies in knowledge- creating sectors such as education and research (Kenway \& al., 2006: 21).

The first policy document, which mentions "knowledge society" is the "European social policy - options for the Union". It speaks directly of the completion of the industrial era and of the revolution, which changed the economic processes (European Commission, 1993: 30). Another document is "Living and working in the information society: people first", published in 1996. Although "information society" is used as a key term, the text talks about a "learning society" to emphasize the concept of lifelong learning and it describes "knowledge society" as a more developed and complete version information society. "The information society will also be a knowledge society in which lifelong learning - in school, at home, in the workplace will be paramount" (European Commission. 1996). An important document (also from 1996) is the annual report on the activities of EU research and technological development. In the document "knowledge society" is associated with: 1). The impact of new technologies on the organization of society. 2). Development of adequate policies with emphasis on scientific and educational policies. 3). The problem of social exclusion. All topics are dealt with in the discourse of employment, social cohesion and knowledge society (European Commission, 1996).

The latest policy documents of the European Commission in which the term "knowledge society" is central are the last two strategies for the development of the EU. The Lisbon Strategy (2000) sets ambitious goal to make the EU "the most competitive and dynamic knowledge-based economy in the world capable of sustainable economic growth and providing more and better jobs and social cohesion" (European Council, 2000). In "Europe 2020", one of the three main priorities is "smart growth and developing an economy based on knowledge and innovation" (European Commission 2010).

In the knowledge society everyday life offers saturation with information presented in all possible forms: texts, sounds, animations that are reproduced with massive customized means, and user activity determines its awareness. According to a survey by the National Statistical Institute (NSI) conducted at the end of 2017 https://www.mediapool.bg/32-ot-domakinstvata-u-nas-nyamat-dostap-do-internet-news272863.html , 67.3\% of households in Bulgaria have access to the Internet and 63\% have a desktop computer, laptop or tablet. The most active Internet users are young people aged 16-24, with $88.1 \%$ using computers or the internet every day. $90 \%$ of university graduates surf regularly on global networks. Most often students use computers $(95.6 \%)$ and $97.8 \%$ regularly surf.

These results have directed us to educational institutions, various approaches used, teaching and learning methods that are part of the mobile learning and are geared towards shaping digital skills so important in the modern world. The digitization of educational processes refers to any form of learning and teaching that is 
based on some kind of technology. Digital skills are an indicator of the development of society, the level of competence of the population, the readiness to accept new challenges in the context of social transformations.

Digital skills form an essential part of e-skills. There is a necessary minimum of digital skills that everyone must possess in order to be able to participate fully in society and in the work process. As the Internet is part of our daily life, most people have access to the internet to take advantage of on-line services, training, networking and information opportunities. The widespread use of digital technologies provides people with access to a large amount of information, which creates a need for a set of access, management, integration and evaluation skills.

The main goal of mobile learning is to improve not only the learning process but also the efficiency of the education system. The foundation of modern educational technologies is the integration of information and communication tools and achievements. What integrates digital technologies and education is enhanced interactivity, based on the concepts of cooperative learning, collaborative learning, e-learning, in order to achieve digital literacy. A basic characteristic of these processes and of mobile learning overall is the pursuit of achieving a certain autonomy of the student. That is why the attention of the specialists is focused on the theories of learning and their application in the teaching of different study subjects.

Mobile learning contributes to the application of the following approaches in education:

1) Learning in experience and through experience. What characterizes the educational technologies in the basis of which learning through experience and in experience is laid, is the creation of real-life situations. In this type of learning tasks close to the life ones have an important place. Specialists talk about so-called authentic tasks. Their solution allows the creation of such an educational environment in which the traditional roles of the teacher and the trainees change. Students acquire the material as an activity in the framework of role discourse situations where they improve their socio-cultural competencies (to fulfil certain social roles in a particular socio-cultural context). This type of learning offers opportunities to use the preliminary knowledge.

2) Problem-based learning is related to solving cognitive problems. In organizing it, the model of scientific knowledge is followed and it is being realized by the following stages:

a. Identifying the general subject by the lecturer, but it may also be formulated by the students. Its importance and relevance to the participants in the research is important.

b. Decomposing the general topic to micro-topics and each group chooses their micro-topic to work. This can be done through brainstorming and through a conceptual network (the key words and the logical connections between them).

c. Planning and implementing the research process.

d. Data collection and preparation of a report on the activity carried out.

e. Presentation of the development through a computer presentation.

f. Assessment of the presentation of each group by the other participants. Criteria discussed in advance, which are accepted by all participants, are used.

3) Global-oriented learning is a concept based on cross-curricular links. The cross-border nature of cognitive activities carried out by learners is a favourable prerequisite for improving their socio-cultural competences as well as the use of knowledge acquired on different subjects and aimed at achieving higher erudition.

Building on these approaches to education and its digitization, mobile learning contributes to the formation of Digital competences including:

- Competence assessment information and knowledge covering the skills needed to find digital content make a critical assessment of it and use it for various purposes - in work or entertainment (Carteli, 2006).

Active Digital Competence - encompasses the skills for producing, validating, editing, enriching and updating digital content (Ilomäki, al., 2011).

- Fair and legal digital citizenship, this is the legitimate way to use copyrighted content (Eshet-Alkalai, 2009).

Competence to use the right tools for human purposes: these are the technical skills to use different tools, e.g. mobile platforms and devices - to understand their potential and limitations. In addition to "computer skills", "ICT competences" (Aesaert et al., 2015) or "digital literacy" (Bawden, 2008). 
Digital competency is described as a confident, critical and creative use of ICT to achieve goals related to work, employability, training, recreation, inclusion and / or participation in society (Ilomäki, al., 2011). Digital competences are seen as a crosscutting key competence enabling people to acquire other key competences such as language, math, learning skills or cultural awareness (Ferrari, Punie \& Brecko, 2013).

Digital competence includes the following areas (Ilomäki, Al, 2011):

- Instrumental use of knowledge.

- Additional skills and knowledge for communication and collaboration, information management, training and problem solving and meaningful participation.

- Attitudes towards the use of strategic skills in intercultural, critical, creative, responsible and automated ways (ALA, 210).

- Culture competence, which covers the understanding of digital culture and to be able to work in a digital environment (Martin, 2006).

Digital competence is the ability to be in line with rapid ICT changes.

\subsection{Empirical Framework}

Methodology is related to several qualitative methods - three focus groups and six In-depth interviews with students and lecturers from South-West University (SWU), Bulgaria. The main topics discussed were: different digital tools used in the training process; mobile learning and its forms and degrees of application in the university environment, the digital literacy of the students.

Fieldwork has been done within the national project "Digital Media Literacy in the context of "Knowledge Society": state and challenges", № КП-06-H25/4, 2018, funded by National Science Fund - Bulgaria. The respondents discussed how students engaged in various kinds of online and offline activities, and how these skills can subsequently affect their specific skills and abilities. Special attention given to the question: whether students were able to find information about the tasks that the professors assigned to research and classes work. Do students think based on self-assessment that they have formed digital skills relating to finding information, communicating, creating content, and ensuring safety.

\subsubsection{Results - Respondents' Views}

The results show that students spend a lot of time on the Internet and social networks. Students have indicated that they use the Internet anywhere. They realistically assess their content-related skills, informational and formal skills. The importance of media and information literacy among young people has increased particularly strongly in the last few years when the media ecosystem was almost overwhelmed by fake news and hybrid media "wars".

According to the teachers, thanks to the digitization of training, the possibilities for organizing the pedagogical interaction here and now, regardless of time, space, the number of the participants in it, the subject of pedagogical communication, etc., expanded. As a new information reality, the digital learning environment creates the conditions for using e-mail, newsgroups, forums for project-based learning; interdisciplinary work.

Teachers share that the successful ICT integration implies the fulfilment of several important requirements: justified use of electronic communication - for example e-mail correspondence to establish contact between the participants; coordination of work between them so that all students would be included, discussing and editing the newsgroup texts, searching for information on the Internet, using multimedia.

Distance learning is another important platform based on digitization and can be used to implement, track and control the learning process; it allows the participation of large groups of people who may be at a distance from one another, to interact with each other in a three-dimensional environment.

Distance learning allows:

- Creating different types of training materials - modules, courses, exercises, tests, online exams, etc.

- Uploading and distribution of files - Word, Excel, PowerPoint, audio and video files.

- Setting group tasks and exercises.

- Tracking the learners' educational progress.

- Creating groups and joining of an unlimited number of users to them. 
Distance learning allows great mobility as well as maintaining activity, upgrading and continuous improvement of the learning process and student achievements as well as their participation in every element of the learning content.

In the focus groups which have been undertaken, students share their satisfaction that they can study without having to attend the university. They say they are remotely prepared by materials, studying uploaded lectures, solving tests, developing independent themes on research projects.

Students say they do not have the opportunity to attend systematically because they work or care for their families, and they think this is the way they can acquire a higher qualification. The lecturers say that in the SWU distance learning is widely used in the form of uploaded materials through the Blackboard platform.

Teachers believe that the implementation of any modern educational technology:

- is elaborated on a specific pedagogical topic or assignment and it is based on a certain methodological and philosophical position of the author;

- provides for a concrete result and mode of implementation, stages through which it is going, specific teaching methods to be used, digital technologies to be provided;

- applies the principles of differentiation and individualization, optimal realization of human and technical possibilities, use of dialogue, communication with trainees;

- suggests ways of evaluating and specific methods for this: criteria and specific indicators to measure results.

Students included in the focus groups shared they use various mobile devices to access the Internet and to surf online. These include computer, laptop, tablet, or smartphone of their own; they also have access to computers in the university classrooms and library. This is why they can be online regularly and for long periods.

They all indicated possessing operative skills to use the Internet, including the mobile Internet. These skills include: easily using the Internet, connecting to a Wi-Fi net; downloading applications for a mobile device; keeping track of, and updating, mobile applications; surfing on the Internet, downloading and uploading files; regulating the privacy settings for dealing with computer viruses and problems in the Internet; working with search engines, like Google and Bing

The surveyed students indicate they possessed systematic Internet skills for quick orientation in a given website, moving from one webpage to another, or easily finding a website they had visited before.

The respondents assessed themselves as having information-related Internet skills, such as: easily finding the information they need, easily examining search results and choosing which to check. They also read news and journals online, and were able to use different strategies for finding Information on the Internet.

Students were confident about their ability to judge whether a website was trustworthy or not; they could compare websites to decide which ones were truthful; they could evaluate the information found online.

Regarding "communication internet skills", the respondents declared they were confidently able to engage in online communication. They freely shared comments in blogs and social networks and were convinced sharing online was risk-free. They were more confident about, and better able to work with Facebook and Messenger than with Twitter and YouTube - perhaps because Twitter is less popular in Bulgaria among online users, while YouTube is mainly used to watch films and listen to music.

Creating content: regarding this skill, the surveyed students declared they could create and upload online content and could make changes in already created content. They stated they had little confidence they could personally create websites and preferred to turn to specialists for this. On the other hand, they knew how to share online video content, write comments on various contents, or create new products out of existing images, music, video.

According to lecturers (participants in the focus groups and in-depth interviews), in order for mobile learning to be effective, it is necessary to emphasize both the improvement of the digital environment of the teaching and learning process and the content side related to students' expectations and the demands of the labor market. Professors say that more effort needed to design on-line courses and lectures in order to provide better training.

Teachers say that the digitization of learning forms a series of skills and qualities that are important for the overall cognitive process and the formation of professional skills such as:

- Deeper Entry into the subject area: search, discovery, awareness and problem-solving skills; questioning skills; 
- Targeting: Skills for gathering and understanding information; to develop critical and alternative thinking - to distinguish facts from opinions and assessments;

- Selection and Interpretation: Skills for Evidence, Metaphorical Thinking, Defining Concepts;

- Combining cognitive content: regrouping the learning material, decision-making skills, associative links, structuring and restructuring;

- Reflexive mechanisms: self-control skills.

Equally important are different social skills that students define as important in order for the training process to be effective: Group work skills; sense of responsibility and self-discipline; Decision-making skills, sense of belonging, risk assessment and risk management skills; Initiation, curiosity and creativity.

\section{CONCLUSION}

In summary, it can be said that digital technologies are widely used in training. Mobile learning has a different degree of application, and it also depends on digital possibilities as a technological environment and its maintenance in the relevant university environment. Computers and the Internet have steadily penetrated the everyday life of people. The digitization of society is ubiquitous and lasting (Bisht, \& Radhakrishnan, 2013). Regular Internet users most often use the global network for communication: connecting with people, expressing themselves, gaining recognition for the created content. At the same time, the rapid pace of change in society and emerging new structures, the generation of new information flows are the basis of modernizing education models in line with digital technologies.

Mobile learning is a combination of successful digitization and the use of its capabilities, with the digital literacy of the students themselves. It creates prerequisites for being part of the global network, linked to the upgrading and dynamic flow of information, fast communication and easy access to various institutions.

The students at South-West University (SWU) and generally young people (18-38) spend much time online in the Internet and the social networks. They pointed out they used Internet everywhere. They made a realistic assessment of their skills in creating content and their informational and formal skills. They know how to create and upload online content and make changes in already created content. They feel confident they can create different kinds of content and online products, including confidence in their skills regarding privacy and knowledge about security equipment and personal data protection; however, they find they have yet more to learn in this field. Overall, their self-assessment is high, which indicates their good knowledge of the digital environment.

The participation of students in the modern digital environment includes access to computers, electronic resources, and other information products and services. It should be taken into account that the acquiring of digital skills for work in an interactive environment improves their efficiency with respect to creatively and innovatively pursuing education activity. Achieving greater effectiveness in training and acquiring knowledge involves the successful use of information and communication technologies, based on acquired skills for seeking and finding useful information and resources, as well as the capacity to analyze and combine the obtained information, to share and discuss different ideas and viewpoints, which they may comment on with their fellow students and teachers.

In this connection, based on the results of the survey presented, it may be said enabling adaptation to the challenges of digital society requires finding more effect pathways to engaging, encouraging, and motivating people to assimilate good theoretical and practical knowledge and skills for working with information and communication technologies. Hence, the efforts of people should generally be guided towards optimizing various ways of using ICT and interactive communication in their work; this may improve their capacity for critical thinking, effective communication and joint problem-solving.

The results of the survey presented indicate which specific skills should be the focus of greater effort in order to make the work of the teachers and the role of education more effective. Engaging young people in short-term or long-term courses could also contribute to their acquirement of important knowledge and qualities related to digital skills. One must not underestimate the conducting of seminars and lecture courses, the possibility of access to online tutorials, electronic textbooks and other means of enhancing digital competence; through these means, it is possible to develop extensive skills for seeking, identifying and critically assessing and using information, and for young people's more independent and creative behaviour in a digital environment. 
For the formation of digital culture, it is of great importance to saturate the work environment with computers, and to include the Internet in the specific responsibilities of those performing different activities. Digital literacy depends on the level of education, age and occupation of individuals. Young and educated people are prone to the formation of digital skills and literacy. The results showed that more efforts needed to improve the approaches to mobile learning, to create Internet security and to take into account the interests of learners.

\section{ACKNOWLEDGEMENT}

The article has been developed in the framework of the research project "Digital Media Literacy in the context of "Knowledge Society": state and challenges" № КП-06-H25/4, funded by National Science Fund - Bulgaria.

\section{REFERENCES}

Aesaert, K., D. Van Nijlen, R. Vanderlinde, J. Tondeur, I. Devlieger, J.Van Braak 2015 "The Contribution of pupil, classroom and school level characteristics to primary school pupils' ICT competences: A performance based $\begin{array}{lllll}\text { approach" Computers } & \text { and } & \text { Education, } & \text { 50-69, }\end{array}$ https://www.sciencedirect.com/science/article/pii/S0360131515000925?via\%3Dihub

American Library Association [ALA] 2010 Strategic Plan 2011-2015, Adopted by the ALA Council, June 28, Retrieved from http://www.ala.org/ aboutala/ missionhistory/plan

Bawden, D. 2008 Origin and Concepts of Digital Literacy In: Digital Literacies: Concepts, policies, and practices. C.Lankshear \& M. Knobel (Eds.). New Yourk: Peter Lang

Bisht, A. \& A.Radhakrishnan. 2013 The Digital Talent Gap Developing Skills for Today's Digital Organizations, Digital Transformation Research Institute, Capgemini Consulting

Cartelli, A. 2006 Teaching in the Knowledge Society: New Skills and Instruments for Teachers. Information Science Publishing.

Cartelli, A. 2013 Fostering $21^{\text {st }}$ Century Digital Literacy and Technical Competency. Information Science Publishing

Eshet-Alkalai, Y., \& Chajut, E. 2009. Changes over time in digital literacy. CyberPsychology \& Behavior, vol.12, number X, pp.713-1715, https://pdfs.semanticscholar.org/b928/b7c4c116bef69d5eb88c989663b42c87bd70.pdf

European Commission. (2010). Europe 2020 <http://eur-lex.europa.eu/legal-content/BG/NOT/?uri=CELEX:52010D

European Council. (2000). Presidency Conclusions Lisbon European Council 23 and 24 march.http://www.consilium.europa.eu/uedocs/cms_data/docs/pressdata/en/ec/00100-r1.en0.htm

European Commission. 1996. Green paper - living and working in the information society: people first

European Commission. (1993). Green paper -European Social Policy - Options for the Union. https://publications.europa.eu/en/publication-detail/-/publication/434c867b-615c-45bc-950b-2512022c2e8b

Ferrari, A., Punie, I., B.N.Brecko 2013 DIGCOMP: A Framework for developing and understanding Digital Competence in Europe. European Commission. Luxembourg, Publication Offices of the EU, http://publications.jrc.ec.europa.eu/repository/bitstream/JRC83167/lb-na-26035-enn.pdf

Henriksen, C. 2011. Media and ICT in a Learning Perspective, Accessed 24 November 2011, Retrieved from http://www.dpu.dk/en/research/ researchprogrammes mediaandict/

Ilomäki, L., Kantosalo, A., \& Lakkala, M. 2011. What is digital competence? In Linked portal. Brussels: European

Schoolnet. http://linked.eun.org/web/guest/in-depth3

Kenway, J., Bullen, E., Fahey, J., \& Robb, S. (2006). Haunting the knowledge economy Retrieved from http://site.ebrary.com/id/10152237

Livingstone, S. (2004) "Media literacy and the challenge of new information and communication technologies" Communication Review, 2004, 1(7), pp.3-14

Martin, A. 2006 European framework for digital literacy, Nordic Journal of Digital Literacy,_02/2006

Measuring Digital Skills across the EU: EU wide indicators of Digital Competence, 2014, https://ec.europa.eu/digitalsingle-market/en/news/measuring-digital-skills-across-eu-eu-wide-indicators-digital-competence

Peicheva, D. \& V.Milenkova "Knowledge Society and Digital Media literacy: Foundations for Social Inclusion and realization in Bulgarian context" Quality of Life, 2017, Vol.1, pp. 50-74

Simpson, A.R. 2001. Raising teens: A synthesis of research and a foundation for action. Boston, M.A.: Center for Health Communication, Harvard School of Public Health 2001. 